\title{
ИНТЕЛЛЕКТУАЛЬНЫЙ АНАЛИЗ ПЕРЕДОВЫХ ТЕХНОЛОГИЙ ЦИФРОВИЗАЦИИ (НА ПРИМЕРЕ ХОЛДИНГА «РОССИЙСКИЕ ЖЕЛЕЗНЫЕ ДОРОГИ»)
}

\author{
(c) 2021 Гулый Илья Михайлович \\ кандидат экономических наук, доцент \\ Петербургский государственный университет путей сообщения Императора Александра I, \\ Россия, Санкт-Петербург \\ E-mail: ilya.guliy@mail.ru
}

Цифровая трансформация означает революционное преобразование и интеграцию цифровых технологий, сервисов во все бизнес-процессы компании. Чтобы оценить процессы цифровизации, внедрения цифровых технологий в компаниях, необходимо исследовать массивы статистических данных конкретных показателей, их абсолютные значения, относительный уровень, динамику. В статье проводится анализ и дается оценка показателей передовых цифровых технологий в холдинге «Российские железные дороги». Цель: проведение оценки, анализа внедрения передовых цифровых технологий в компании «Российские железные дороги» за последние годы. Методы: интеллектуальный анализ данных, сравнение, структурирование массивов данных. Результаты: рассмотрены статистические показатели оценки внедрения передовых цифровых технологий в крупнейшей железнодорожной компании мира «Российские железные дороги», проведен их анализ. Практическая значимость: проведенное исследование дает возможность проводить оценку масштабов цифровизации на основе исследования результатов статистического наблюдения, углубляет методическую базу корпоративного анализа процессов цифровой трансформации.

Ключевые слова: цифровизация, передовые цицровые технологии, интеллектуальный анализ данных, Российские железные дороги.

Введение

Экономическая оценка тенденций процессов цифровой трансформации, происходящих в компаниях, отраслевых комплексах, представляет собой конкретный инструмент, на основе которого можно дать заключение о реальной ситуации цифровизации, ее результатах, эффективности [2].

Большой потенциал имеет оценка показателей официальной статистической отчетности, ежегодно публикуемой Росстатом. В частности, статистики передовых цифровых технологий в отраслях производства и сферы услуг [3].

\section{Результаты исследований}

Рассмотрим возможности статистических массивов больших данных разработки и использования передовых цифровых технологий для их интеллектуального анализа.

Ключевым показателем, отражающим результаты развития процессов цифровизации, выступает показатель количества используемых передовых технологий, в том числе их динамики, структуры и т.д. Массивы больших данных представлены в разрезе: видов технологий, срока ис- пользования (по годам внедрения), источников (собственная разработка, приобретение в стране, зарубежные); защиты прав на использования (наличие патента); уровню новизны (принципиально новая в мировой экономике, новая на уровне страны).

Проведем анализ использования передовых технологий в холдинге «РЖД» в динамике за ряд лет.

На рисунке 1 приведены графические данные по динамике числа использованных передовых технологий в целом и по годам внедрения. Отметим повышательный тренд использования технологий с 2015 по 2019 гг. (ежегодный прирост на уровне 13\%) и сокращение на $18 \%$ в 2020 г., обусловленное консервацией части технологий в условиях падения спроса на перевозки в период пандемии. По уровню хронологической новизны наибольшая доли приходится на технологии, внедренные 6 и более лет ранее (их доля в общем количестве выросла за 6 лет с 64 до 79\%). На технологии, внедренные до 1 года, приходится 5\%, от 1 до 3 лет - 11\%.

На рисунке 2 приведена динамика количества передовых технологий по холдингу «РЖД» 


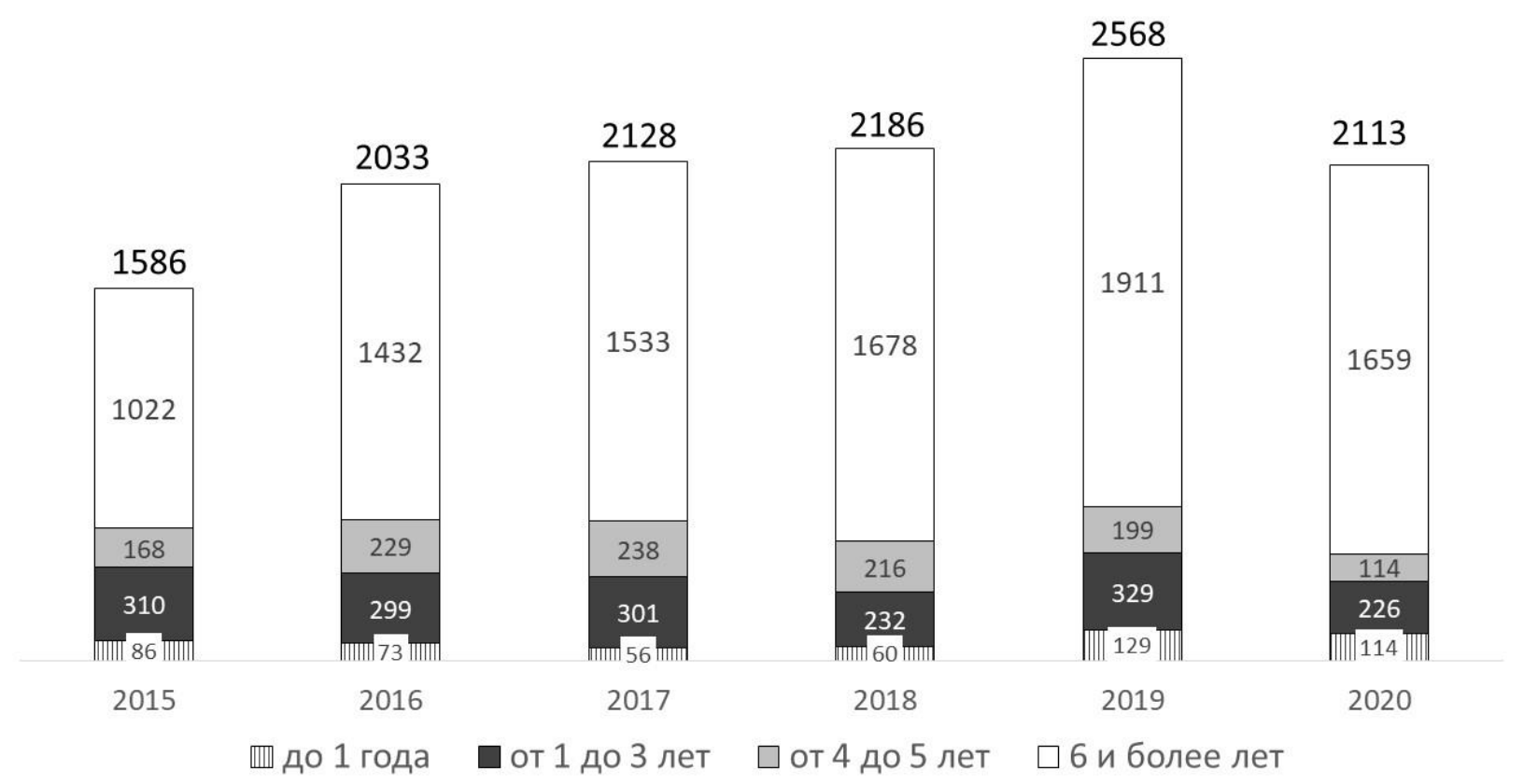

Puc. 1. Динамика числа использованных передовых технологий по годам внедрения в холдинге «Российские железные дороги» с 2015 по 2020 гг., единиц Источник: построено автором на основе [3].

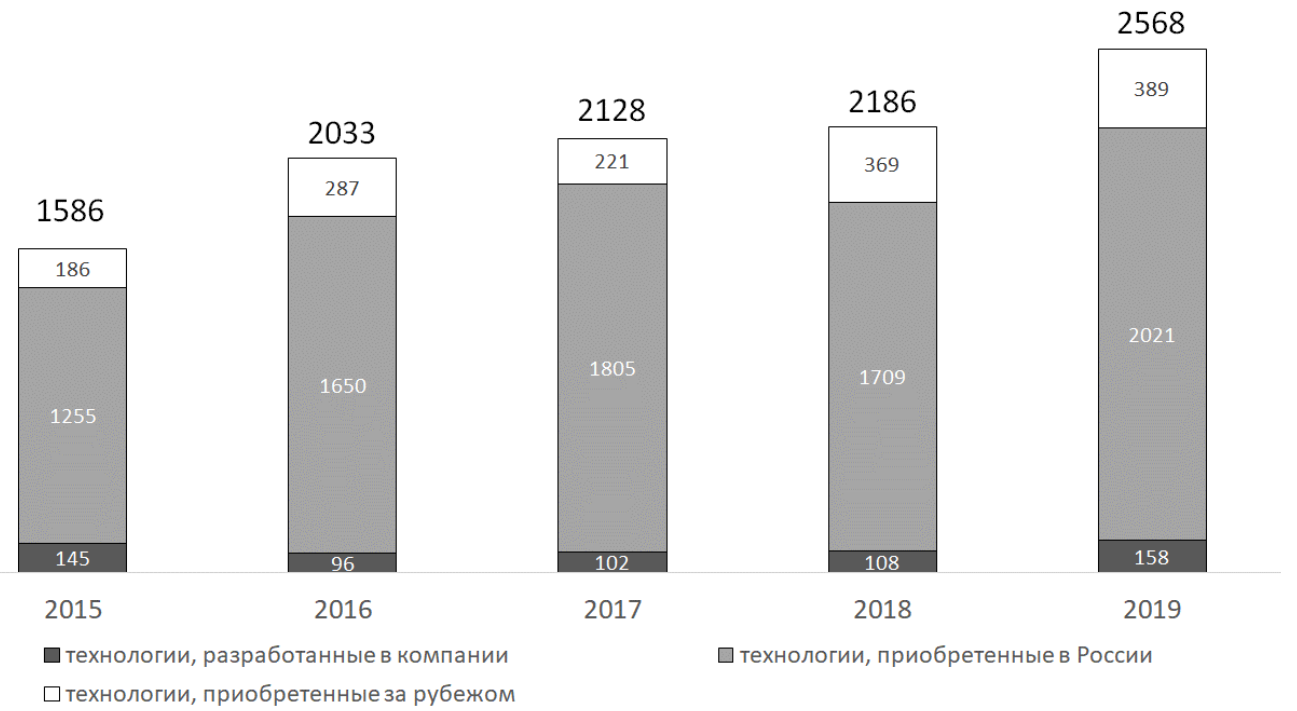

Puc. 2. Структура числа использованных передовых технологий

в холдинге «Российские железные дороги» по местам разработки с 2015 по 2019 гт., единиц Источник: построено автором на основе [3].

в разрезе локаций разработки. Наибольшая доля (79\%) в общем количестве применяемых технологий в 2019 году приходилась на разработанные в России (таким образом, сохраняются позиции импортонезависимости), 15\% на приобретенные за рубежом и 6\% - разработка самой компанией.

Видовая структура используемых передовых технологий приведена на рисунке 3. Можем оценить, какие конкретно технологии внедрены в холдинге, какова скорость внедрения технологий конкретного вида [5].

Около 56\% общего количества технологий приходится на видовую группу «связь и управление». По количеству здесь преобладают технологии локальной компьютерной сети компании и обмена электронной информацией, а по динамике внедрения за 2015-2019 гг.- програм- 


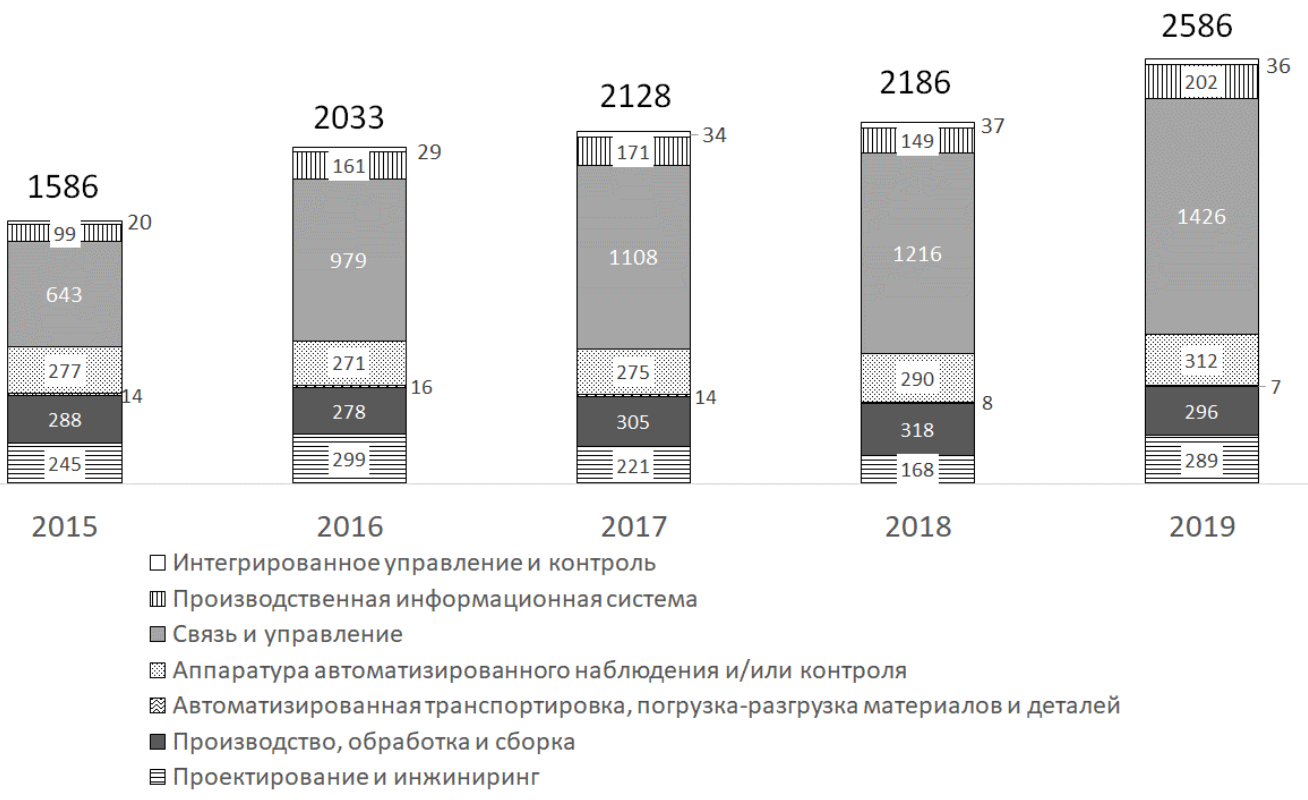

Puc. 3. Структура числа используемых передовых технологий по видам в холдинге «Российские железные дороги» с 2015 по 2019 гг., единиц

Примечание: за 2020 г. данные не представлены по причине изменения содержания и формулировок видов цифровых технологий

Источник: построено автором на основе [3].

мируемые логические контроллеры и системы передачи со спектральным уплотнением на транспортных сетях.

На видовую классификационную группу «аппаратура автоматизированного наблюдения и контроля» приходится $12 \%$ общего количества технологий. Проектирование и инжиниринг занимает третье место по количественному охвату в компании (11\%). Наибольшими темами внедрения внутри этой группы отмечены технологии цифрового представления результатов компьютерного проектирования, используемое в управлении снабжением (рост с 18 до 39 единиц).

Почти двукратный рост технологий характеризует группу «производственная информационная система».

С 2017 года в компании внедрена одна технология искусственного интеллекта. Число используемых систем супервизорного управления и системы сбора и накопления информации выросло с 16 до 29 единиц.

Сравнение количества технологий на единицу добавленной стоимости по холдингу с экономикой в целом в 2020 г. позволил выделить наиболее успешные направления реализации пилотных проектов в «РЖД»: промышленные роботы с системами сенсоров / технического зрения; беспилотные транспортные средства, программное обеспечение для управления взаимоотношениями с клиентами (CRM), программы для прогнозирования и планирования спроса, технологии обработки потоковых данных / мониторинга в реальном времени, средства генерации энергии посредством альтернативных источников, бережливое производство.

Статистические массивы больших данных дают возможность оценить степень влияния и эффекты внедрения передовых цифровых технологий [1]. По холдингу наибольшая результативность отмечается в отношении роста производительности труда, повышения качества услуг, соответствия стандартам, повышения скорости и снижения времени операционного цикла, повышения степени гибкости и адаптации к изменениям (рисунок 4).

Наличие отдельных единиц цифровых технологий в холдинге «РЖД» по классификации [4] также возможно оценить по статистическим массивам данных [3] (таблица «Число используемых передовых производственных технологий по годам внедрения» по ОКВЭД и ОКОГУ).

Ранжируя количественные данные в разрезе 9 групп сквозных технологий, отметим наиболее распространенные виды технологий:

1. Системы распределенного реестра (все- 


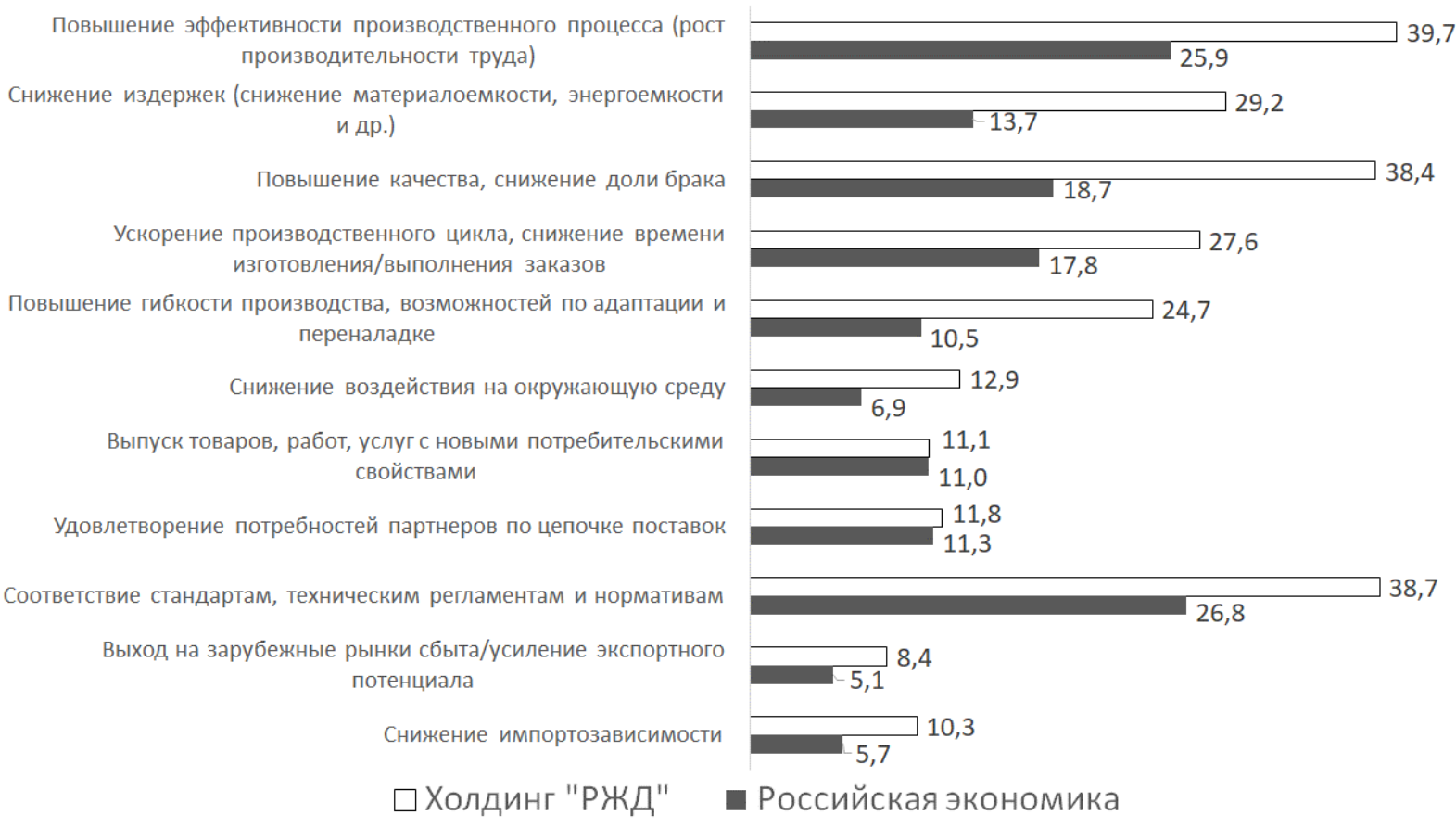

Puc. 4. Доля (удельный вес) организаций, оценивших отдельные эффекты внедрения передовых цифровых технологий со степенью воздействия «очень высокая», процентов от общего числа организаций в соответствующей сфере

Примечание: по российской экономике данные приведены по результатам обследования 15089 организаций, по холдингу «Российские железные дороги» - 380 организаций и подразделений холдинга.

Источник: построено автором на основе [3].

го 462 единицы), среди которых: межфирменные компьютерные сети, включая Экстранет и электронный обмен данными (EDI) (319 единиц), программное обеспечение для управления взаимоотношениями с клиентами (CRM) (140 единиц);

2. Технологии беспроводной связи (265 ед.): включая технологии беспроводной связи для производства (254 ед.);

3. Промышленный интернет (260 позиций): в частности, глобальные системы навигации (ГЛОНАСС, GPS и др.) (164 единицы); автоматизированные системы контроля (56 единиц);

4. Большие данные (189 единиц), в рамках которых наибольшее количество по видам: планирование ресурсов предприятия (ERP) (59); технологии обработки потоковых данных/мониторинга в реальном времени (40); планирование производственных ресурсов (MRP II) (37); программное обеспечение для прогнозирования спроса или планирования спроса (24); система управления складом (WMS) (12); система управления транспортировкой (9); технологии обработки больших данных (8).
Заключение

Таким образом, можно заключить, что интеллектуальный анализ процессов цифровой трансформации дает важную информацию, показывает ситуацию и тенденции в сфере внедрения новых технологий. По холдингу «Российские железные дороги» количество использованных передовых цифровых технологий за последние годы в целом растет, около трех четвертей от общего количества приходится на российские образцы, порядка 6\% производится силами самой компании. Более половины от общего количества технологий приходится на группу «связь и управление», «аппаратура автоматизированного наблюдения и контроля» занимает $12 \%$, «проектирование и инжиниринг» занимает третье место (11\%). Сравнение количества технологий по «Российским железным дорогам» со средним уровнем по российской экономике позволил выявить успешные направления пилотной цифровизации в холдинге: промышленные роботы; беспилотные транспортные средства, CRM-системы, программы для прогнозирования спроса, технологии обработки потоковых данных и онлайн-мониторинга, бережливое производство. 


\section{Библиографический список}

1. Zhuravleva N.A.,PoliakM. Architecture of managing big data of mixed transportation of passengers in aglomerations // IOP Conference Series: Materials Science and Engineering. 8. VIII International Scientific Conference Transport of Siberia 2020, 2020. P. 012055.

2. Методические рекомендации по цифровой трансформации государственных корпораций и компаний с государственным участием [Электронный ресурс]. URL: https://digital.gov.ru (дата обращения: 31.10.21).

3. Результаты федерального статистического наблюдения по форме № 1-технология «Сведения о разработке и использовании передовых производственных технологий» [Электронный ресурс]. URL: https://rosstat.gov. $\mathrm{ru}$ (дата обращения: 31.10.2021).

4. Стратегия цифровой трансформации ОАО «РЖД» до 2025 г.: утв. Советом директоров ОАО «РЖД» 25.10.2019 [Электронный ресурc]. URL: https://consultant.ru. (дата обращения: 20.10.21).

5. Чеченова Л.М. Методика комплексной оценки организации как инструмент планирования и прогнозирования ее эффективного развития // Бюллетень результатов научных исследований. 2021. № 2. С. 69-81. 